Article

\title{
Sustainable Tourism Cities: Linking Idol Attachment to Sense of Place
}

\author{
Jiayu Zhou ${ }^{1}$, Yerin Yhee ${ }^{2}$, , Eunmi Kim ${ }^{3}$, Jin-Young Kim ${ }^{2}$ and Chulmo Koo ${ }^{2, *}$ \\ 1 Department of Convention and Exhibition Management, Kyung Hee University, Seoul 02447, Korea; \\ zhoujiayu724@naver.com \\ 2 Smart Tourism Education Platform, Kyung Hee University, Seoul 02447, Korea; rin95923@gmail.com (Y.Y.); \\ jk293@khu.ac.kr (J.-Y.K.) \\ 3 Smart Tourism Research Center, Kyung Hee University, Seoul 02447, Korea; keunmi100@gmail.com \\ * Correspondence: helmetgu@khu.ac.kr
}

Citation: Zhou, J.; Yhee, Y.; Kim, E.; Kim, J.-Y.; Koo, C. Sustainable Tourism Cities: Linking Idol Attachment to Sense of Place. Sustainability 2021, 13, 2763. https://doi.org/10.3390/su13052763

Academic Editor: José Luís Abrantes

Received: 8 January 2021

Accepted: 22 February 2021

Published: 4 March 2021

Publisher's Note: MDPI stays neutral with regard to jurisdictional claims in published maps and institutional affiliations.

Copyright: (C) 2021 by the authors. Licensee MDPI, Basel, Switzerland. This article is an open access article distributed under the terms and conditions of the Creative Commons Attribution (CC BY) license (https:/ / creativecommons.org/licenses/by/ $4.0 /)$.
Abstract: With the development of the "Hallyu" (Korean Wave) and people's deep understanding of South Korea, the phenomenon of "Hallyu" idols driving tourism has become very common. Tourists, especially fans are no longer satisfied with the traditional tourist attractions with special symbolic meanings when visiting South Korea, but instead focus on common places associated with idols. For example, restaurants, cafes, bookstores, parks and convenience stores that have appeared in an idol's social network accounts. With the application of the theory of attachment and sense of place in the tourism field, this study will start from the celebrity attachment, to exploring the specific processes and mechanisms by which idols affect the behavioral intentions of the fans. The associations between visitors and idol-related places based on celebrity attachments has also become possible, and the fans/tourists' opinions and attitudes toward idol-related places will also change due to this emotional attachment. Relevant data were collected in the form of online questionnaires, and 440 valid responses were finalized for data analysis. Through data analysis, all the hypotheses proposed in this paper are supported, and there are significant relationships and positive influences among the variables. Data analysis results show that idol attachment can positively influence the four cognitive dimensions of sense of place (place identity, place dependence, social bonding and atmosphere). The various dimensions of sense of place can promote the generation of place attachment.

Keywords: celebrity attachment; idol attachment; sense of place; place attachment; behavioral intention

\section{Introduction}

With the diversification of cultural forms and the development of modern technology and network media, more and more tourists begin to travel with the purpose and motivation of pop culture, such as games, animation, idol music and so on [1]. These phenomena can be easily found in the tourism field. On Twitter, an account named "BTS places" is dedicated to posting information about BTS-related places and has more than 27,000 followers, with more than 10,000 likes and 4000 retweets of popular posts. "Weibo", China's social networking site, has a "super topic" that is where fans gather to discuss their favorite idols. Whether searching "Idol name + place name" directly on Weibo or entering any idol-related place name in an idol's super topic, you can see various fans discussing, recommending and visiting these locations directly. For example, in the super topic of Bangtan Sonyeondan (BTS), there are searches for "coffee shop" (the recording scene of BTS's Entertainment program), "BTS bus stop" (the bus stop of a scene in BTS's music video), "Blue Sky park" (a park where BTS members have visited) and so on. Not only can you see messages, pictures and related records, but even fans make these locations into a travel guide, indicating the route for other fans to find and visit. There are many ways to find many idol-related places and the visiting records of fans on social media and websites. 
The role of celebrities such as singers, movie stars, and sports stars who are subject to envy and attachment in brand endorsements has been widely studied. As a common phenomenon in the market, brands are using celebrities' high popularity and wide-ranging popularity to improve their image and enhance the equity [2]. The familiarity, attractiveness, credibility, and expertise of celebrities to the public make their endorsement effective [3]. In many early studies, fans were considered to be the pathological existence of alienation from society, and the criticism and negative evaluation of fans' fanatical behavior always existed [4]. However, with the deepening of research on cultural economy, many researchers have begun to regard fans as a normal phenomenon that prevails in society. Fan activities have rational and positive aspects, which are not only conducive to the formation of cultural capital, but also play an effective role in the generation and accumulation of social capital [5]. The cultural industry in the current environment is exporting pop idols to the audience at an unimaginable speed and scale.

Particularly, a new market segment in special interest tourism, pop culture tourism has emerged in that individuals travel to destinations mainly driven by pop culture or relative media themes such as movies, music, and celebrities [6]. Media and pop culture have been significant agents of South Korea's recent image. Pop culture and idols played a role in creating a positive image while news media covering natural disasters and political and social issues induced a negative image [7]. For fans, their favorite idols played a significant role in weakening a negative image of destination and strengthening a positive image of destination. That is, celebrities are directly involved with creating new sustainable destination images. As a group that accepts and consumes, fans can not only obtain personal benefits but also realize the acquisition of pop culture capital through the close connection with social pop culture.

These examples show that in the eyes of fans, some places are not only physical buildings and environments. They endow these places with special meaning, in which they get in touch with their idols and communicate with other fans, and thus they have special emotions and attachments toward places [8]. Attachment is the synthesis of emotional connections and bonds between people and objects, and it is a subjective emotional consciousness and overall emotional range [9]. When consumers think that celebrities endorse a product out of attachment or trust rather than purely because of money, they will show a more positive evaluation and reaction to the corresponding product, so that the endorsement effect will be better [3]. These phenomena are also no exception in contexts of place choice (i.e., destination of tourists). Celebrities, as representatives of popular culture, play an important role in consumer attitudes and behaviors in public life including tourism behavior as well as choosing products and brands. That is, not only the attachment to celebrities but also the attachment to a place can be generated and developed in the social interaction and environmental evaluation of a place [10].

To fill the current gap in the literature, the destinations as research objects in this study are the places involved in the idols' daily lives (such as restaurants, coffee shops, bookstores, parks, etc.), which are attractive to fans due to the idols' accidental visits. ICTs, specially social media, are changing our daily life and we can easily look at other people's life through social media [11]. Based on the above example, these places are closer to the idols' real lives and easier to get in touch with the local lifestyle. On the other hand, these places have not been officially advertised or endorsed by idols. Compared with traditional hot spots or landmarks, fans think that these places, unrelated to money and advertising, are more credible, and they are more likely to react and evaluate positively [3].

Therefore, the purpose of this study is to research the specific process and mechanism of idol attachment affecting fans' behavioral intention of their "clock in" travel. The main research questions are as follows: (1) How does fans' attachment to idols affect their perceptions of idol-related places? (2) Can the multi-faceted perception of the place encourage fans to develop emotional attachment to the place itself? and (3) How does place attachment affect the behavioral intentions of fans? We use sense of place theory and attachment theory to develop the research model and propose specific factors. Idol 
attachment as an independent variable affects the four dimensions of sense of place (i.e., place identity, place dependence, idol bonding and atmosphere), which further affect the place attachment and ultimately influence three dimensions of behavioral intention (i.e., purchase intention, destination preference and information sharing). In order to carry out empirical verification of our research model, this study mainly adopts online surveys, and the data comes from the fan groups on Weibo.

\section{Literature Reviews}

\subsection{Celebrity-Induced Tourism}

Celebrities create and stimulate tourists' travel needs and influence the process of choosing their destination. In other words, celebrities can directly or indirectly form the motivation of tourists' intentions and behaviors [12-14]. The popular culture in the context of modern technology and diversified media plays an important role in people's lives with increasing influence, and such phenomena and effects are more obvious among young people. A survey by Boon and Lomore [15] shows that young people often say that celebrities have a strong attraction for them. Celebrities refer to a wide variety of objects among which film actors or musicians play a major role. The study also revealed that more than half $(59 \%)$ of the respondents indicated that their attitudes and beliefs were positively influenced by their idols, and that such influences can spread to their sporting activities, literary creation and work.

Actually, different studies of how celebrities drive the travel behavior of tourists or fans have different views. On the one hand, the familiarity of visitors with destinations is considered to be one of the influential factors of destination decisions. Familiarity does not necessarily come from a direct visit, but may also come from indirect experiences created in the form of media or other people's evaluations [16]. For tourists who have never visited the destination, their familiarity with the destination is very subjective. As an example, fans who have participated in celebrity-related activities feel that they are already familiar with the destination [17]. Fans' love and attachment to celebrities motivate them to search for information more actively. Through learning language, local culture and other content, they can have realistic or abstract communication with celebrities, thus increasing their familiarity with destinations [18]. Baloglu [19] shows that tourists' knowledge of destinations can reduce their perceived risk and uncertainty of destinations, which makes them more likely to have a sense of safety and confidence in destinations. On the other hand, some researchers argue that there is a certain contradiction between the familiarity and novelty of the destination. Tourists' positive perception and intention to visit the destination are not always positively correlated with the familiarity, and how to achieve the best balance between them has become another topic that needs to be studied. In spite of this, there is still a large body of research demonstrating the positive impact of familiarity on tourism preferences $[4,16,17]$.

The composition and evaluation of destination images have always had diverse dimensions, and researchers generally believe that destination images significantly affect the process of tourists' destination selection [12,20,21]. However, once it comes to tourism decision-making and actual tourism behaviors, emotional components become particularly important, and the choices people make are often influenced by their positive or negative emotions [22]. At the same time, fans' enthusiasm for celebrities can translate into their acceptance of celebrity-related destinations. In other words, the idea that celebrities can catalyze viewers' access to certain destinations has been confirmed, and celebrities can be a major attraction of a place [23]. Therefore, the influence of celebrities on certain specific places and the tourism behaviors based on celebrity attachment are worth discussing.

\subsection{Attachment Theory}

Bowlby ([24], p. 201) defined attachment as "the tendency of human beings to make solid affectional bonds to particular people and objects". Attachment theory was originally proposed to explain the attachment of children to their mothers in the field of psycho- 
analysis and has been extended to the study of adolescents' and adults' functioning in their current relationships [25]. With regard to attachment theory, Thomson et al. [26] explained many types of objects that people can form emotional attachments with, including celebrities, place, gifts, brands, and other things that they are interested in and have special preferences for. The attachment formed on such a variety of objects can affect our attitudes for that and emotions like love, worship, passion and so on. A core principle of these emotions is the sense of belonging. That is, when individuals get along with objects that they think are safe and comfortable, the generations of attachment will become universal regardless of the individual's cultural background [27].

Therefore, according to the previous theory and the purpose of the objects of this study, attachment is defined as a deep and strong emotional and psychological connection between a subject and a specific object. Here, the object may refer to a person or thing, and also can refer to an individual or a group. People do not have an attachment to every object they come into contact with, but once attachments are generated, it means that they will have a commitment to the product, brand, or someone. The stronger the attachment, the higher the subject's loyalty to the object. For example, consumers will be willing to spend more money to buy a product they are attached to, or make an investment in the person they are attached to [28]. The more people are attached to a figure or an object, the more they want to shorten the distance between them. Giles and Maltby [29] pointed out that an individual's commitment to the object can remain stable even in the face of difficulties. The attachment of an individual can be said to be a relatively long-lasting, firm, and profound emotion. It comes from the interaction and recollection of individuals and objects, carries the close connection between the two, and makes the individual take corresponding actions.

With the deepening and development of various researches, attachment theory has been widely applied in marketing, social relations, online communities, and other fields [30,31]. Attachment in the context of tourism has been highlighted by the affective and positive ties developed from individual connections with a celebrity or destination [32]. In some studies on tourism and destinations, it is found that tourists' attachment to destinations changes their attitudes toward the destination and further affects their subsequent actions and activities [33]. Especially, Thomson et al. [26] explained that celebrities are also regarded as a human brand, and a long-term relationship between consumers and celebrities can last when consumers view celebrities as objects of intimacy and likability and attachment. Celebrities are well-known people who have made significant achievements in certain areas, including actors, singers, models, sports stars, businessmen, politicians and so on [34]. Celebrities not only have a reputation and honor in the minds of fans and audiences, but also can become a guide for the direction of public life [18]. Previous studies pointed out that the meaning of celebrity attachment was that people admired and followed the figures who were far away from themselves, and attachment could also play a corresponding role in social and emotional aspects [29]. It can be said that the degree of attachment can be used as a good basis for predicting the form and nature of the interaction between the subject and the object. Conversely, subjects' attachment strength can also be inferred from their psychology and behavior [26].

\subsection{Idol and Place Attachment}

As a kind of celebrity, the idol group, which has emerged with the worldwide K-pop craze, forms a relationship with fans that goes beyond the traditional celebrity attachment. For fans, the attachment to the idol creates close and rich emotional connections and feelings belonging to the idol [35]. That is, fans not only have adoration and love for idols but fans will try to develop close connections with idols for enriching this emotion. Fans want to feel that their idols are by their side, and this kind of emotional interaction is not necessarily to constitute a substantial experience (i.e., meet their idol directly such as fanmeetings or concerts) [36]. The stronger the fans' attachment to their idols, the more they tend to keep a close relationship with their idols. The common ways to connect with idols 
include using various means of communications [37], purchasing idol-related peripheral products and souvenirs [38], and, of course, going to an idol-related place (i.e., the idol-run cafeteria, an idol's agency, a concert hall, etc.) for travel experience [39]. Therefore, the association between visitors and idol-related places based on celebrity attachments has also become possible, and the fans' / tourists' opinions and attitudes toward idol-related places will also change due to this emotional attachment [35]. Furthermore, these attachments of their idol can transfer to products or places related to them because of the symbolic meaning attached by fans [40].

Place attachment also developed on the basis of attachment theory, which mainly reflects the emotions between people and specific places and environments from the perspective of social relations [32]. Attachment to the place occurs when there is an important significance between the subject and others, or it is not so much the attachment of people to the building and the physical environment rather than the mutual bond between people [41]. The subjects (i.e., fans) will regard the objects (i.e., places) of attachment as a self-extension, so they have a positive tendency towards the objects they are attached to. This is different from other affective dimensions such as 'loyalty', because loyalty is based on convenience or inertia, while attachment is a more intense behavioral, motivational, and emotional feature $[8,42,43]$. At the same time, attachment to the place differs from attachment to brand or tangible goods. Brand/product attachment tends to be 'category' whereas place attachment tends to a particular subject (such as idols, culture, or history). That is, fans have strong spiritual sustenance for idols and have symbolic meaning; so for fans, the actual places related to idols are full of emotional meaning from the social perspective [33]. Therefore, place attachment must study the social relations formed in the place, and the perception and association of the physical dimension are only part of the attachment, rather than the whole or the result.

\subsection{Sense of Place}

Human engagement within a place connects materiality to meaning [44], in an open and ongoing process [45], that brings together social, cultural, and natural dimensions of place. The experience of engagement and interaction requires presence (being in) and action (being with), always influenced by physical, historical, social, and cultural aspects that, together, contribute to creating a shared sense of place. Sense of place is constructed from particular interactions and mutual articulations of social experiences embedded within subjective and emotional attachments $[45,46]$. In other words, sense of place is actually the perception and feeling of people, not the place itself [47] because sense of place makes certain places to have unique and special characteristics and fosters people's attachment and belonging to it [48]. In the view of many theorists, the effect between people and places is bidirectional [49]. Tuan's [50] research pointed out that sense of place means that people endow a place with specific meaning through their perception of local attributes and values. Stedman [51] added sociological thinking on the basis of environmental psychology, arguing that connections between human and environment and people's perception of the environment influence human behavior. That is, sense of place is described as people's identification, attachment, and dependence on the place.

Sense of place has also begun to play an important role in the context of tourism development. Tourists' expectations for place or destinations, perceived value and overall satisfaction of tourism experience can be studied with reference to the contents explained by sense of place. In previous studies in the context of tourism, some researchers conceptualized sense of place as several dimensions of evaluation, such as place identity, place dependence, social bonding and place attachment (see Table 1). Brocato et al. [8] proposed three main dimensions to understand the quality of sense of place, namely place identity, place dependence and social bonding. Specially, Deutsch et al. [49] suggested sense of place by incorporating the concepts of place satisfaction, community and atmosphere into their study. In this study, we selected five dimensions of sense of place for an explorative 
relationship between idol attachment and place attachment of fans: place identity, place dependence, social bonding, atmosphere and place attachment.

Table 1. The dimensions of sense of place in previous studies.

\begin{tabular}{ccccccc}
\hline Dimensions & [52] & [53] & [49] & [8] & [54] & [55] \\
\hline Place Identity & $\sqrt{ }$ & $\sqrt{ }$ & $\sqrt{ }$ & $\sqrt{ }$ & $\sqrt{ }$ & $\sqrt{ }$ \\
Place Dependence & $\sqrt{ }$ & $\sqrt{ }$ & $\sqrt{ }$ & $\sqrt{ }$ & $\sqrt{ }$ & $\sqrt{ }$ \\
Place Attachment & $\sqrt{ }$ & & $\sqrt{ }$ & & & \\
Atmosphere & & & $\sqrt{ }$ & $\sqrt{ }$ & & \\
Social bond & & & $\sqrt{ }$ & & & \\
Community & $\sqrt{ }$ & $\sqrt{ }$ & & & & \\
Sustenance & & $\sqrt{ }$ & & & $\sqrt{ }$ & $\sqrt{ }$ \\
$\quad$ Nature & & & $\sqrt{ }$ & & $\sqrt{ }$ & $\sqrt{ }$ \\
Place Satisfaction & & & & & $\sqrt{ }$ & \\
Place Meanings & & & & & & \\
Social Ties & & & & & & \\
Place Characteristics & & & & &
\end{tabular}

Prettyx et al., 2003: [52]; Davenport \& Anderson, 2005: [53]; Deutsch et al., 2013: [49]; Brocato et al., 2015: [8]; Azizi, 2018: [54]; Eaton et al., 2019: [55].

Place identity (PI) refers to the personal identity that conforms to the physical and social aspects of the place, that is, personal image embodied and relevant in the physical environment [56]. The core meaning of this concept also involves the social identity theory [57], which indicates that individuals hold multiple social identities by dividing themselves into different social groups. PI arises when individuals accumulate placerelated experience [58], and contains localized experience from the perspective of social attributes. It can also involve other people's views and memories of the place [59,60]. Place dependence (PD) was defined in Stokols's [61] study of individual's perceived intensity of the associations between individuals and specific places. Backlund and Williams [62] argued that PD was an individual's assessment and evaluation of the functions of the environment, that is, to what extent the environment can satisfy the needs of an individual. PD can also refer to the degree to which a place differs from other preparatory or alternative options in meeting the requirement of the target [63]. Therefore, PD is a subject's reliance on the environment as interpreted from a functional perspective [64]. Social bonding means the bonds between people formed in a particular area. The community, culture, and interpersonal relationships that occur in the physical environment are the conditions and premises for a strong emotional bond. So, social factors must be considered in addition to physical space [47]. Ramkissonn's [65] study regarded social bonding as a cognitive dimension based on the consideration of interpersonal relationship. Deutsch et al. [49] also suggested the atmosphere (AT), other dimensions of sense of place, which means the surrounding environmental ambience from an aesthetic perspective. This dimension is considered to play an aesthetic and physical level of the place. Not only that, when a person has more ways to travel, for example, they can drive by themselves, and they are likely to visit a location because of the atmosphere.

\section{Research Model and Hypothesis Development}

\subsection{Research Model}

To investigate the role of idol attachment and the outcomes, we propose the research model shown in Figure 1 based on the prior theoretical basis of attachment theory and sense of place. Figure 1 illustrated the research model of celebrities and celebrity-related places. The derivation of the research model is based on the prior theoretical based celebrity attachment, sense of place and attachment theory. We propose 12 hypotheses to study a complete process. As above, in the literature review, in recent research on the field of tourism, the places involved in previous studies have special meanings and symbols, such as celebrities' former residences. Or people can establish fixed social relationships in these 
places, such as particular residential area, community or service company. However, the places to be studied in this article can be seen everywhere in daily life and they are not strongly symbolic. It is only because these common places are visited by idols that they have some meaning in the minds of fans. Fans travel to these places in real life and form a popular tourist phenomenon. So, starting from idol attachment, we point out its influence on the dimensions of sense of place and place attachment, ultimately pointing to a number of behaviors and intentions.

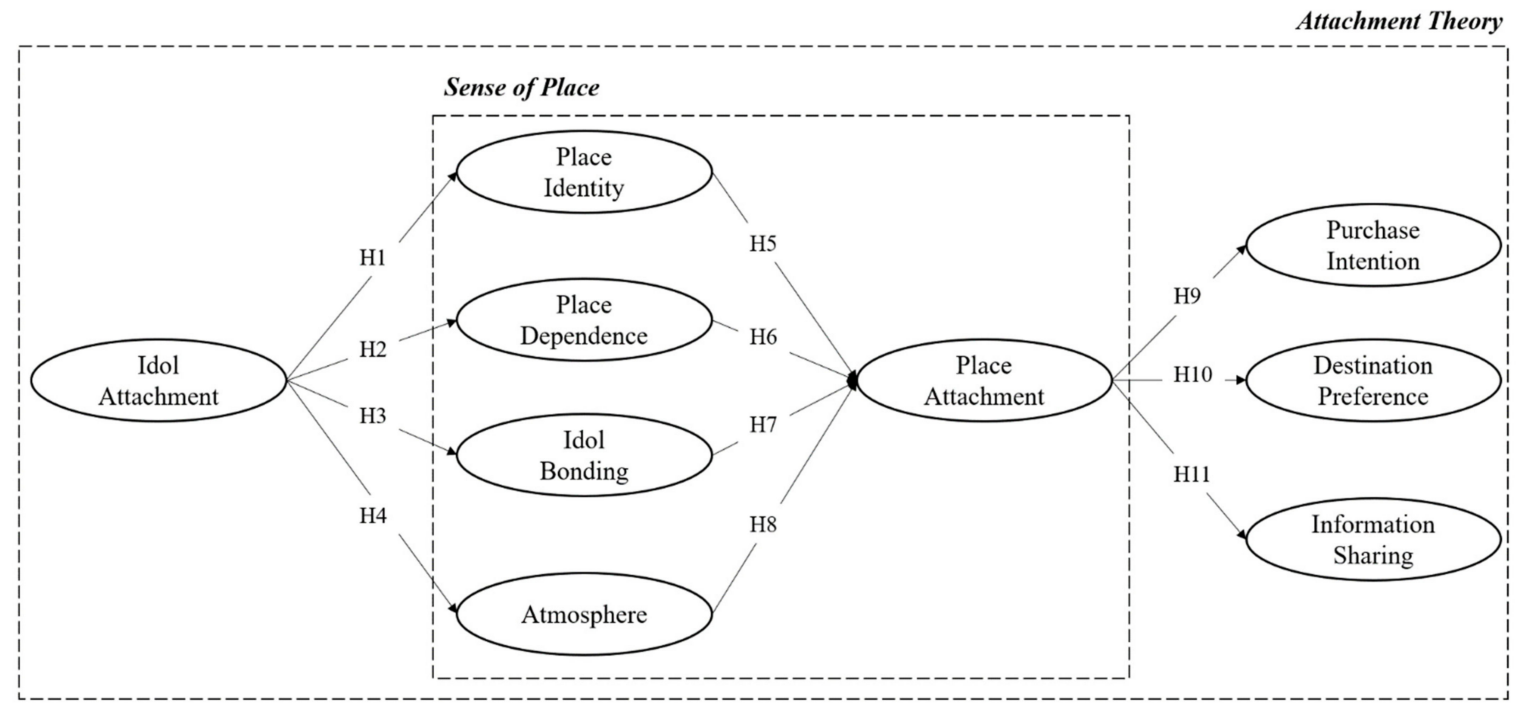

Figure 1. Research model.

\subsection{Hypothesis Development}

\subsubsection{Effects of Idol Attachment}

Attachment is a kind of lasting emotional connection and the subject's attachment to the object can be transferred, for example, from the person to the place [66]. Almost all studies on emotional attachment have shown the idea that individuals want to stay close to the objects they are attached to, and the stronger the attachment of the subject to the object, the more eager the subject is to establish various connections with the object $[26,38]$. The meaning transfer model of McCracken [40] also pointed out that the symbolic meaning attached by individuals to celebrities will be transferred to products related to celebrities, that is, individuals will have the same emotion for products endorsed by celebrities due to their positive impressions, good evaluations, and emotional attachments to celebrities [18]. Kim [37]'s research proved that celebrities not only enhance individuals' interest in destinations, but also further lead to a series of behavioral intentions. Su et al. [35] pointed out that the close or estranged relationship between audience and celebrities will affect their attitudes and impressions about the relevant places.

Fans constantly learn about, contact with, and expose themselves to the environment or scene associated with celebrities because of their love for celebrities. Fans can also further promote their association and sense of belonging to relevant places while establishing their attachment to celebrities [67]. That is, idol attachment makes a particular place symbolic to fans and reflect their identity as fans $[8,51,66]$. When people believe that these specific locations can meet their needs and achieve their goals, PD on the functional level comes from this [38].

Social bonding is generated by the interaction between the subject and the object. Based on this concept, this paper puts forward the concept of idol bonding (IB), which means the social and interpersonal bond between the fans and idols in the idol-related place [8]. Celebrity attachment is a common positive psychological commitment of fans to idols. Although the interaction between fans and idols is one-way and abstract in most cases, celebrities are still a source for fans to realize self-cognition and obtain social 
relationships and cultural capital [18]. This is reflected in the fact that for many fans, they will follow the idol's steps to make choices and activities. These behaviors can not only reflect their identity as fans, but also meet their needs and establish various interpersonal relationships [66]. In addition, it is impossible for fans to completely break away from their attachment to idols when they judge the things related to idols. Therefore, the aesthetics and behavior of idols largely affect the judgment standards and value orientation of fans [29]. Lee et al. [68] argued that attachment to stars has the effect of shaping the image of a destination. When celebrities become the motives for tourists to travel, their travel experience and decision-making behavior are more influenced by celebrities. Tourists' high interest and love for celebrities is a key reason for changing the image of the destination in their eyes [69]. The atmosphere is the perception of the aesthetic level of the destination and is part of the destination image [70].

Therefore, the prediction effect of idol attachment on each dimension of sense of place can be assumed as follows:

Hypothesis 1 (H1). Idol attachment positively influences place identity.

Hypothesis 2 (H2). Idol attachment positively influences place dependence.

Hypothesis 3 (H3). Idol attachment positively influences idol bonding.

Hypothesis 4 (H4). Idol attachment positively influences atmosphere.

\subsubsection{Sense of Place Predicted Place Attachment}

The PI in the marketing environment demonstrates that self-identification can be derived from the consistency of an individual's identity and the related locations [71]. Individuals in a fanbase may rely on idol-related places to gain and support their social identity as fans. When individuals use the environment as a means of communication and a way of self-expression and achieve the consistency of personal image and environmental image in this process, they will have attachment to the place. PI is essentially the selfconnection between individuals and places [8].

PD means that individuals tend to reduce the likelihood of choosing alternatives when faced with multiple options, which also means that a specific location is more irreplaceable to the individual [8]. Based on the arguments of environmental psychology, functional assessment is a very important factor in reflecting the role of the place in supporting and providing desired goals [72]. In addition, the stronger the ability of a place to meet personal needs, the more positive one's perception of that place will be [49]. Therefore, by improving the completion of the needs of the place to the consumer, it can promote the generation of positive emotions and evaluations, thus driving the enhancement of place attachment. Especially for entertainment venues and expenses, specific locations are more attractive, thus PD affects individuals' attachment on locations [8,33].

Pretty et al. [52] demonstrated that social interaction and association with others is one of the most important sources of place attachment. Social bonding can include families, friends, and communities, which are as important as actual physical location in forming place attachments [73]. Some studies discovered the possibility of creating social bonds based on a service environment, such as a possible friendship between employees and customers. When individuals seek emotional support, they are also supported by other roles in society, thereby enhancing the attachment to each other [74].

Brocato et al. [8] explored the relationship between the various dimensions of sense of place and place attachment in the study, demonstrating that PI, PD, and social bonds between visitors and local people can strengthen the attachment toward place. The sense of place also contains the physical environment, and the concept of the atmosphere. Even though interpersonal relationships and social components are often concerned in predicting the attitudes of visitors, the role of the physical environment should not be overlooked [51]. 
Therefore, Stedman [51] came to the conclusion that the environment and landscape have predictive power for attachment. Based on the above research, we propose the following four hypotheses:

Hypothesis 5 (H5). Place identity positively influences place attachment.

Hypothesis 6 (H6). Place dependence positively influences place attachment.

Hypothesis 7 (H7). Idol bonding positively influences place attachment.

Hypothesis 8 (H8). Atmosphere positively influences place attachment.

\subsubsection{Place Attachment and Outcomes}

Based on the significant influence of place attachment on the individual's emotional attitudes, psychological intentions and decision-making behaviors toward places, the purpose of cultivating and establishing place attachment is to achieve a long-lasting relationship between tourists and places/destinations [42]. This study will speculate and analyze the impact of place attachment on subsequent behaviors and intentions from the following three concepts.

First is the intention to purchase idol-related products. Purchase intention (PIN) means the possibility of fans' intentions to purchase idol-related products when they are visiting the idol-related places [75]. Although from the emotional point of view, attachment to a celebrity can constitute a direct motivation for a visitor's behavior. However, for some people who focus on the location (such as moviegoers), they are more likely to go to places where celebrities have appeared to purchase and collect relevant products [38,75]. Many fans and spectators are keen to imitate and reproduce the situation when visiting their idol-related destinations, especially when they buy the same food, clothing and products to feel the intimacy with the place and the scene [76] (Robinson, 2015). In the research of marketing, it has been proven that the customer's attachment to the brand can greatly influence their shopping behavior [77].

The second is the destination preference (DP), which refers to tourists' preference for a specific destination compared to other destinations, or, tourists will prefer to visit some particular destinations [78]. DP is a dimension of destination loyalty, that is to say, tourists are more inclined to choose their preferred destinations in the decision-making process [41]. A person's attachment to a particular place implies a close emotional bond between the two, especially a positive emotional connection between the individual and the environment. This attachment can be expressed as shortening the distance to the place or maintaining the relationship with the place in other ways [66]. An individual's attachment to the place can be manifested in greater tolerance to the location, and individuals are willing to invest in order to promote the proximity of mutual relations, while they will even avoid contacting similar alternative objects [42]. Kil et al. [79] demonstrated that a visitor's attachment on a place positively influences their preferences in selecting a destination.

Different individuals in a particular context can reach consensus or build partnerships through sharing, and the standpoint that people can achieve their goals and gain happiness by sharing their life experiences is also supported [80]. When attachment involves group activities, individuals in the social group tend to share knowledge with others in the group [81]. The motivation to share knowledge is not only to focus on the relationship between oneself and others, but also to establish connections between others [82]. With the development of the Internet and diverse mobile technologies, fans easily acquired information and shared various experience [83]. Fans' participation in idol-related places is relatively active and forms a group with the same identity, so people will be willing to share information [31]. Wu and Cheng [84] said that the trust and satisfaction gained in the experience will affect people's attitude and willingness to share knowledge.

Based on the above research results, this paper proposes three hypotheses as follow-up to outcomes of place attachment: 
Hypothesis 9 (H9). Place attachment positively influences purchase intention.

Hypothesis 10 (H10). Place attachment positively influences destination preference.

Hypothesis 11 (H11). Place attachment positively influences information sharing.

\section{Methodology}

\subsection{Measures}

The process of developing the questionnaire was divided into three parts to ensure the interval validity: (1) using English as the initial questionnaire language, (2) the original version of the English questionnaire was translated into Chinese by researchers who are both good at English and Chinese, (3) the 35 measurement items involved in the questionnaire were developed based on previous studies. Therefore, the reliability and validity of each construct have been verified. In addition, a group of academic experts is still asked to evaluate the questionnaire items to ensure the content validity.

The first part of the questionnaire consists of nine variables: (1) the initial independent variable is 'idol attachment', (2) 'place identity', 'place dependence', 'idol bonding' and 'atmosphere' are the four cognitive dimensions from sense of place, (3) the variable 'place attachment' of the affective dimension and (4) the final output results include three dependent variables of 'purchase intention', 'destination preference' and 'information sharing'. A total of 35 items were generated based on the above nine factors, all of which used the 7-point Likert scale $(1=$ strongly disagree, $7=$ strongly agree $)$. Taking into account the problem of measurement error rates, a multi-item scale was used to construct the questionnaire [85]. All items used in this study are shown in Table 2.

Table 2. Operational definitions of constructs.

\begin{tabular}{|c|c|c|}
\hline Variables & Operational Definitions & Reference \\
\hline Place (Idol-related Place) & $\begin{array}{l}\text { Specific sites/locations associated with idols, } \\
\text { including physical buildings and environments. }\end{array}$ & $\begin{array}{l}\text { Brocato } \\
\text { et al., } 2015\end{array}$ \\
\hline Idol Attachment & Strong emotional connection of fans to idols. & $\begin{array}{c}\text { Giles and } \\
\text { Maltby, } 2004\end{array}$ \\
\hline Sense of Place & $\begin{array}{l}\text { Fans' perceptions of the functional and cognitive } \\
\text { dimensions of idol-related places. }\end{array}$ & $\begin{array}{l}\text { Brocato } \\
\text { et al., } 2015\end{array}$ \\
\hline Place Identity & $\begin{array}{c}\text { The congruence between a fan's identity/image and } \\
\text { the idol-related place. }\end{array}$ & $\begin{array}{l}\text { Proshansky, } \\
1978\end{array}$ \\
\hline Place Dependence & $\begin{array}{c}\text { Compared to other places, fans' evaluation of the } \\
\text { degree to which idol-related places can meet } \\
\text { their requirements. }\end{array}$ & $\begin{array}{l}\text { Backlund and } \\
\text { Wiliams, } 2003\end{array}$ \\
\hline Idol Bonding & $\begin{array}{l}\text { The social and interpersonal bond between the fans } \\
\text { and idols in the idol-related place. }\end{array}$ & $\begin{array}{l}\text { Brocato } \\
\text { et al., } 2015\end{array}$ \\
\hline Atmosphere & $\begin{array}{l}\text { Visitors' aesthetic perception of the surrounding } \\
\text { environment and ambience. }\end{array}$ & $\begin{array}{l}\text { Deutsch } \\
\text { et al., } 2013\end{array}$ \\
\hline Place Attachment & $\begin{array}{l}\text { Strong emotional bonds between fans and } \\
\text { idol-related places. }\end{array}$ & $\begin{array}{l}\text { Brocato } \\
\text { et al., } 2015\end{array}$ \\
\hline Purchase Intention & $\begin{array}{l}\text { The possibility of visitors' intentions to purchase } \\
\text { idol-related products. }\end{array}$ & $\begin{array}{l}\text { Kim } \\
\text { et al., } 2019\end{array}$ \\
\hline Destination Preference & $\begin{array}{l}\text { Tourists' preference and inclination of a specific } \\
\text { destination compared with other destinations. }\end{array}$ & $\begin{array}{c}\text { Lee } \\
\text { et al., } 2012\end{array}$ \\
\hline Information Sharing & $\begin{array}{l}\text { The intention and desire of individuals to share their } \\
\text { experiences with others. }\end{array}$ & $\begin{array}{l}\text { Kwon } \\
\text { et al., } 2015\end{array}$ \\
\hline
\end{tabular}




\subsection{Data Collection}

Data collection was done online. The questionnaire was published on a survey website in China named 'Tencent Questionnaire' (http:/ /wj.qq.com/, accessed on 23 April 2019). The respondents were asked to be fans who had visited South Korea and encouraged the respondents to participate in the survey through lottery. In order to confirm that the respondent is a fan of K-pop, we selected the 'super topic' of BTS on the Chinese social networking site 'Weibo' to publish the questionnaire link. 'Super topic' is a topic tag named after the idol (similar to the tag in Twitter). Generally speaking, users who follow 'super topic' and post comments in it can be considered as fans of an idol. As for whether the fan has visited South Korea, it is confirmed by the question, "The number of times I have visited South Korea" in advance.

A total of 510 responses were received, and 440 responses were retained and used in subsequent analysis after elimination and screening. Table 3 summarizes the demographic characteristics of the respondents. Considering that the respondents are the fan groups of male idol singers, the vast majority of respondents were female $(n=384,89.5 \%)$, and the age distribution is also concentrated in the under-30s (below 20, $n=147,33.4 \%$; 20 29 years old, $n=290,65.9 \%$ ). Since the questionnaire was published on a Chinese social networking site and survey website, almost all of the respondents live in Asia $(n=435$, $98.9 \%)$. The student group ( $n=360,81.8 \%$ ) accounted for the largest proportion, while more than three-quarters of the respondents have a college education $(n=338,76.8 \%)$, followed by high school students $(n=75,17 \%)$.

Table 3. Demographics of respondents.

\begin{tabular}{|c|c|c|c|c|c|}
\hline Variables & $n$ & $\%$ & Variables & $n$ & $\%$ \\
\hline \multicolumn{3}{|c|}{ Gender } & \multicolumn{3}{|c|}{ Previous visit to Korea } \\
\hline Male & 46 & 10.5 & First & 219 & 49.8 \\
\hline Female & 394 & 89.5 & Second & 111 & 25.2 \\
\hline \multicolumn{3}{|c|}{ Age } & Third & 56 & 12.7 \\
\hline Below 20 & 147 & 33.4 & Fourth & 19 & 4.3 \\
\hline $20-29$ & 290 & 65.9 & More than fifth & 25 & 5.7 \\
\hline 30-39 & 2 & 0.5 & $\begin{array}{l}\text { Foreigner living } \\
\text { in Korea }\end{array}$ & 10 & 2.3 \\
\hline $40-49$ & 1 & 0.2 & \multicolumn{3}{|c|}{ Previous visits to idol-related places } \\
\hline \multicolumn{3}{|c|}{ Nationality region } & First & 160 & 36.4 \\
\hline Asia & 435 & 98.9 & Second & 115 & 26.1 \\
\hline Europe & 1 & 0.2 & Third & 68 & 15.5 \\
\hline North America & 3 & 0.7 & Fourth & 18 & 4.1 \\
\hline America & 1 & 0.2 & More than fifth & 79 & 18.0 \\
\hline \multicolumn{3}{|c|}{ Education } & \multicolumn{3}{|c|}{ Job } \\
\hline $\begin{array}{l}\text { Middle school } \\
\text { or below }\end{array}$ & 6 & 1.4 & Student & 360 & 81.8 \\
\hline High school & 75 & 17.0 & Office worker & 67 & 15.2 \\
\hline Bachelor & 338 & 76.8 & Professional & 5 & 1.1 \\
\hline Master & 19 & 4.3 & Self-employed & 1 & 0.2 \\
\hline Doctor & 2 & 0.5 & Other & 7 & 1.6 \\
\hline
\end{tabular}




\section{Analysis and Results}

\subsection{Data Analysis}

To test the proposed research model, we used a partial least squares (PLS) analysis. Partial least squares (PLS) is commonly used to establish and test theory, and the predictive power of the research model can be known by load degree and path coefficients. Previous studies have detailed the various dimensions of sense of place [49], among which PI and PD are quite widely mentioned and studied. Brocato et al. [8] added the concept of social bonds (between consumers and employees) to explore how consumers get attached to a particular service location of the service company and trigger a series of positive consumer behaviors. After some analysis and discussion on previous research, we believe that for fans, the spatial sense of idol-related places is indeed based on "people", but the location does not only mean the existence and establishment of interpersonal relationships. In some cases, the "place" itself can also be a motivation for their choice, especially if the style or ambience of the site matches their aesthetics. Therefore, we also incorporated the consideration of the dimension of atmosphere, comprehensively studying the four functional and cognitive dimensions of the sense of place with idol attachment as the cause and place attachment as the consequence. In this paper, a total of 11 hypotheses are proposed to explore whether idol attachment can affect multiple cognitive and functional dimensions of sense of place, thus affecting place attachment and generating a series of behavioral intentions. To verify that such a relatively complex relationship can be established, PLS path modeling can be used [86]. In addition, PLS can be applied to both large and small samples, so this paper conducts data analysis by performing PLS using Smart PLS 3.0 [87].

\subsection{Measurement Model}

To validate our measurement model, we assessed content, convergent, and discriminant validity. First, the content validity of our survey was examined from the existing prior literature, and our measurements were developed by adopting constructs validated by other experts. Second, a confirmatory factor analysis (CFA) was performed on the measurement model and the convergent validity and discriminant validity were tested [88]. The criteria were as follows: factor loadings of all items should be greater than 0.5 (or ideally 0.708 ) in the $95 \%$ confidence level; value of average variance extracted (AVE) of all factors should be greater than 0.5 . To ensure internal consistency of each variable, the value of Cronbach's alpha should be greater than 0.7. The threshold of composite reliability (CR) should not be lower than 0.7 to ensure reliability $[85,86,89,90]$. Discriminant validity is judged by comparing the square root of AVE for each latent variable and the inter-construct correlations. If the value of the former is greater than that of the latter, it indicates that there is sufficient discriminant validity between the variables [91]. Table 4 shows the relevant results of the CFA.

Specifically, the value of CR ranges from 0.852 to 0.949 , all above the required threshold of 0.7. The values of Cronbach's alpha are all greater than 0.7 (ranging from 0.739 to 0.934 ) which passed the test of internal consistency reliability. All loadings of items are greater than 0.7 (ranging from 0.726 to 0.922 ), and the AVE values for variables are greater than 0.5 (ranging from 0.656 to 0.790 ). All the above indicate that the latent variables in the model have convergent validity. The square root of AVE of each variable is greater than 0.8 and also meets the requirement that these values should be greater than internalconstruct correlations values, thus demonstrating that the discriminant validity between the dimensions is also sufficient. The specific values are shown in Table 5. 
Table 4. Analysis of reliability and convergent validity.

\begin{tabular}{|c|c|c|c|c|c|}
\hline Variables & Items & Loadings & A & C.R. & AVE \\
\hline \multirow{3}{*}{$\begin{array}{c}\text { Idol } \\
\text { Attachment (IA) }\end{array}$} & IA1: I love my idols. & 0.831 & \multirow{3}{*}{0.805} & \multirow{3}{*}{0.884} & \multirow{3}{*}{0.719} \\
\hline & IA2: I am affectionate to my idols. & 0.886 & & & \\
\hline & IA3: I am obsessed with my idols. & 0.824 & & & \\
\hline \multirow{3}{*}{$\begin{array}{c}\text { Place } \\
\text { Identity (PI) }\end{array}$} & PI1: The idol-related places reflects that I am a fan. & 0.897 & \multirow{3}{*}{0.868} & \multirow{3}{*}{0.918} & \multirow{3}{*}{0.790} \\
\hline & PI2: Visiting idol-related places says a lot about me as a fan. & 0.885 & & & \\
\hline & PI3: I feel that I can really be a fan in the idol-related places. & 0.883 & & & \\
\hline \multirow{3}{*}{$\begin{array}{c}\text { Place } \\
\text { Dependence (PD) }\end{array}$} & $\begin{array}{l}\text { PD1: The idol-related places meet my needs better than any } \\
\text { other places. }\end{array}$ & 0.867 & \multirow{3}{*}{0.801} & \multirow{3}{*}{0.883} & \multirow{3}{*}{0.717} \\
\hline & $\begin{array}{l}\text { PD2: I get more satisfaction out of visiting idol-related places than } \\
\text { any other places. }\end{array}$ & 0.880 & & & \\
\hline & $\begin{array}{l}\text { PD3: I enjoy visiting the idol-related places more than any } \\
\text { other places. }\end{array}$ & 0.790 & & & \\
\hline \multirow{3}{*}{ Idol Bonding (IB) } & $\begin{array}{l}\text { IB1: I have a lot of fond memories with my idol in the } \\
\text { idol-related places. }\end{array}$ & 0.824 & \multirow{3}{*}{0.808} & \multirow{3}{*}{0.887} & \multirow{3}{*}{0.723} \\
\hline & IB2: I have a special connection to my idols at the idol-related places. & 0.874 & & & \\
\hline & IB3: I feel very close to my idols when I visit the idol-related places. & 0.852 & & & \\
\hline \multirow{5}{*}{ Atmosphere (AT) } & AT1: The idol-related places have appealing architectures. & 0.850 & \multirow{5}{*}{0.901} & \multirow{5}{*}{0.927} & \multirow{5}{*}{0.717} \\
\hline & AT2: The idol-related places have beautiful buildings. & 0.858 & & & \\
\hline & $\begin{array}{l}\text { AT3: The idol-related places have a peaceful and } \\
\text { relaxing atmosphere. }\end{array}$ & 0.808 & & & \\
\hline & $\begin{array}{l}\text { AT4: The idol-related places have a comfortable and pretty } \\
\text { decoration style. }\end{array}$ & 0.880 & & & \\
\hline & AT5: The idol-related places have clean streets and alleys. & 0.835 & & & \\
\hline \multirow{3}{*}{$\begin{array}{c}\text { Place } \\
\text { Attachment (PA) }\end{array}$} & $\begin{array}{l}\text { PA1: I will miss the idol-related places when I am away from them } \\
\text { for too long. }\end{array}$ & 0.833 & \multirow{3}{*}{0.739} & \multirow{3}{*}{0.852} & \multirow{3}{*}{0.657} \\
\hline & PA2: I would be disappointed if the idol-related places did not exist. & 0.820 & & & \\
\hline & PA3: I can't imagine stopping to visit the idol-related places. & 0.779 & & & \\
\hline \multirow{4}{*}{$\begin{array}{l}\text { Purchase Intention } \\
\text { (PIN) }\end{array}$} & PIN1: I will buy clothes or jewellery as those are worn by my idols. & 0.803 & \multirow{4}{*}{0.826} & \multirow{4}{*}{0.884} & \multirow{4}{*}{0.656} \\
\hline & PIN2: I will buy products endorsed by my idols. & 0.860 & & & \\
\hline & PIN3: I will buy the food or drink my idols have eaten. & 0.845 & & & \\
\hline & $\begin{array}{l}\text { PIN4: I will buy other peripheral products related to my idol (such as } \\
\text { cartoon dolls). }\end{array}$ & 0.726 & & & \\
\hline & DP1: South Korea was my first choice. & 0.772 & & & \\
\hline & DP2: South Korea is more attractive than any other country. & 0.861 & & & \\
\hline & $\begin{array}{l}\text { DP3: I'm more interested in visiting South Korea than any } \\
\text { other country. }\end{array}$ & 0.898 & & & \\
\hline $\begin{array}{l}\text { Destination Preference } \\
\text { (DP) }\end{array}$ & $\begin{array}{l}\text { DP4: I would prefer visiting/being in South Korea, rather than going } \\
\text { to other countries. }\end{array}$ & 0.909 & 0.926 & 0.942 & 0.730 \\
\hline & $\begin{array}{l}\text { DP5: I would rank South Korea as the most enjoyable country among } \\
\text { the others I have visited. }\end{array}$ & 0.862 & & & \\
\hline & $\begin{array}{l}\text { DP6: South Korea provides the best recreation/leisure opportunities } \\
\text { among the alternatives I have visited/been. }\end{array}$ & 0.818 & & & \\
\hline & IS1: I intend to keep sharing my visiting experiences. & 0.867 & & & \\
\hline & IS2: I plan to share my visiting experiences with other fans. & 0.922 & & & \\
\hline Information Sharing & $\begin{array}{l}\text { IS3: I will share my visiting experiences with other fans in the } \\
\text { near future. }\end{array}$ & 0.895 & 0.934 & 0949 & 0790 \\
\hline & $\begin{array}{l}\text { IS4: I will say positive things about my visiting experiences to } \\
\text { other fans. }\end{array}$ & 0.904 & & & \\
\hline & $\begin{array}{l}\text { IS5: I would strongly recommend my visiting experiences to } \\
\text { other fans. }\end{array}$ & 0.854 & & & \\
\hline
\end{tabular}


Table 5. Analysis of discriminant validity.

\begin{tabular}{|c|c|c|c|c|c|c|c|c|c|}
\hline Constructs & (1) & (2) & (3) & (4) & (5) & (6) & (7) & (8) & (9) \\
\hline IA & 0.848 & & & & & & & & \\
\hline PI & 0.250 & 0.889 & & & & & & & \\
\hline PD & 0.270 & 0.561 & 0.847 & & & & & & \\
\hline IB & 0.317 & 0.479 & 0.564 & 0.850 & & & & & \\
\hline $\mathrm{AT}$ & 0.289 & 0.287 & 0.418 & 0.421 & 0.847 & & & & \\
\hline PA & 0.253 & 0.412 & 0.517 & 0.497 & 0.400 & 0.811 & & & \\
\hline PIN & 0.351 & 0.289 & 0.339 & 0.422 & 0.376 & 0.318 & 0.810 & & \\
\hline DP & 0.226 & 0.342 & 0.455 & 0.430 & 0.355 & 0.433 & 0.324 & 0.855 & \\
\hline IS & 0.257 & 0.233 & 0.316 & 0.392 & 0.319 & 0.296 & 0.395 & 0.336 & 0.889 \\
\hline
\end{tabular}

Notes: Diagonal values in bold are the square root of $\mathrm{AVE}$. IA = idol attachment; $\mathrm{PI}=$ place identity; $\mathrm{PD}=$ place dependence; $\mathrm{IB}=$ idol bonding; $\mathrm{AT}=$ atmosphere; $\mathrm{PA}$ = place attachment; $\mathrm{PIN}$ = purchase intention; $\mathrm{DP}=$ destination preference; IS = information sharing

\subsection{Structural Model}

After the test of reliability and validity of the measurement model, we also used PLS 3.0 to verify each hypothesis proposed in the model. Figure 2 displays the outcome of the structural model. The structural model was built and tested using 5000-capacity bootstrapping samples for their explanatory power and path significance [92]. Table 6 shows the results of the hypothesis tests.

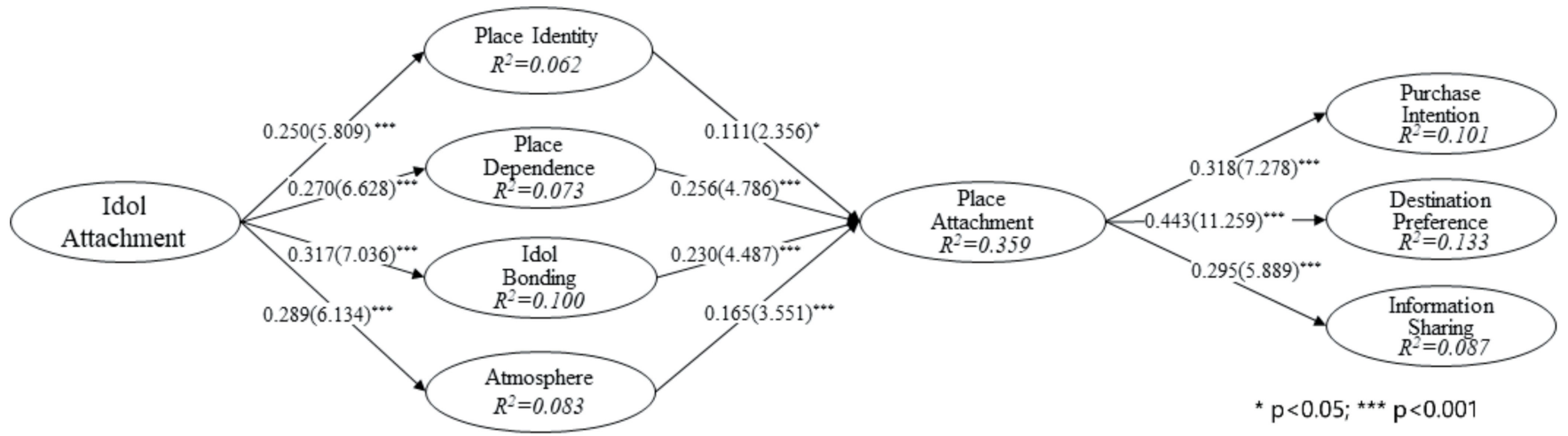

Figure 2. Results of SEM Analysis.

According to the test results of hypotheses, first of all, idol attachment has a significant impact on place identity, place dependence, idol bonding and atmosphere. $\mathrm{H} 1$ to $\mathrm{H} 4$ are supported, $\mathrm{H} 1(\beta=0.250, \mathrm{t}=5.809, p<0.001), \mathrm{H} 2(\beta=0.270, \mathrm{t}=6.628, p<0.001), \mathrm{H} 3$ $(\beta=0.317, \mathrm{t}=7.036, p<0.001)$ and $\mathrm{H} 4(\beta=0.289, \mathrm{t}=6.134, p<0.001)$. The $\mathrm{R}^{2}$ value of PI, PD, IB and AT are separately 0.062, 0.073, 0.100 and 0.083. Among them, the largest value of $\mathrm{R} 2$ is idol bonding, which means that idol bonding has the strongest explanatory power relatively among these for dimensions. The hypotheses of $\mathrm{H} 5$ to $\mathrm{H} 8$ are designed to explore whether the perception of functional and cognitive dimensions can have an impact on place attachment, and the results show that these four hypotheses are also supported. H5 ( $\beta=0.111, \mathrm{t}=2.356, p<0.05), \mathrm{H} 6(\beta=0.256, \mathrm{t}=4.786, p<0.001), \mathrm{H} 7$ $(\beta=0.230, \mathrm{t}=4.487, p<0.001)$ and H8 $(\beta=0.156, \mathrm{t}=3.551, p<0.001)$. According to the $R 2$ value, place attachment is 0.359 , which means that $35.9 \%$ of the variation of PA can be explained by the four dimensions of sense of place. Hypotheses H9 to H11 are to explore the behavioral intention and selection bias of the fans induced by place attachment. H9 $(\beta=0.318, \mathrm{t}=7.278, p<0.001), \mathrm{H} 10(\beta=0.443, \mathrm{t}=11.259, p<0.001)$, and H11 $(\beta=0.295$, 
$t=5.889, p<0.001)$. Therefore, the three hypotheses proposed last are supported. Place attachment can positively impact on fans' purchase intention, destination preference and their intention to share information.

Table 6. Results of the hypothesis tests.

\begin{tabular}{|c|c|c|c|c|}
\hline \multirow{2}{*}{\multicolumn{2}{|c|}{ Hypotheses }} & \multicolumn{3}{|c|}{ Standardized Path Coefficients } \\
\hline & & $\beta$ & $t$-Value & Results \\
\hline $\mathrm{H} 1$ & $\begin{array}{l}\text { Idol attachment positively influences } \\
\text { place identity. }\end{array}$ & 0.250 & $5.809^{* * *}$ & Supported \\
\hline $\mathrm{H} 2$ & $\begin{array}{l}\text { Idol attachment positively influences } \\
\text { place dependence. }\end{array}$ & 0.270 & $6.628^{* * *}$ & Supported \\
\hline $\mathrm{H} 3$ & $\begin{array}{l}\text { Idol attachment positively influences } \\
\text { idol bonding. }\end{array}$ & 0.317 & $7.036^{* * *}$ & Supported \\
\hline $\mathrm{H} 4$ & Idol attachment positively influences atmosphere. & 0.289 & $6.134^{* * *}$ & Supported \\
\hline H5 & $\begin{array}{l}\text { Place identity positively influences } \\
\text { place attachment. }\end{array}$ & 0.111 & $2.356^{*}$ & Supported \\
\hline H6 & $\begin{array}{l}\text { Place dependence positively influences } \\
\text { place attachment. }\end{array}$ & 0.256 & $4.786^{* * *}$ & Supported \\
\hline $\mathrm{H} 7$ & $\begin{array}{l}\text { Idol bonding positively influences } \\
\text { place attachment. }\end{array}$ & 0.230 & $4.487^{* * *}$ & Supported \\
\hline H8 & $\begin{array}{l}\text { Atmosphere positively influences } \\
\text { place attachment. }\end{array}$ & 0.165 & $3.551 * * *$ & Supported \\
\hline H9 & $\begin{array}{l}\text { Place attachment positively influences } \\
\text { purchase intention. }\end{array}$ & 0.318 & $7.278^{* * *}$ & Supported \\
\hline H10 & $\begin{array}{l}\text { Place attachment positively influences } \\
\text { destination preference. }\end{array}$ & 0.443 & $11.259^{* * *}$ & Supported \\
\hline H11 & $\begin{array}{l}\text { Place attachment positively influences } \\
\text { information sharing. }\end{array}$ & 0.295 & $5.889^{* * *}$ & Supported \\
\hline
\end{tabular}

Through data analysis, all the hypotheses proposed in this paper are supported, and there are significant relationships and positive influences among the variables. Idol attachment can be used as an antecedent of sense of place. Sense of place has a predictive effect on place attachment and promotes the formation of place attachment. Place attachment induces and triggers fans' intention to purchase and share information, and they are more likely to choose the relevant destination country.

\section{Discussion}

The $\mathrm{H} 1$ to $\mathrm{H} 4$ have been supported to prove that the idol attachment can be used as an antecedent to affect the fans' perception and judgment of places. On the one hand, fans believe that idol-related places can reflect their identity and meet their needs, and they can feel social connections with idols when visiting these places. At the same time, in many cases, these places themselves conform to their aesthetics, but only by the carrier of the idol for fans to know. This is consistent with previous studies examining the associations and effects between idols and destinations $[3,18,69]$. This phenomenon can also be explained according to the point of meaning transfer, which means that fans have a higher acceptance of the places related to their idols [18].

On the question of whether sense of place can promote the generation of place attachment, according to the support of $\mathrm{H} 5$ to H8, the answer is yes. Different studies have different standpoints and propositions on whether the cognitive dimension comes first or the affective dimension comes first when people perceive perceptions of places. However, the former's point of view is supported in this study. People's knowledge of places generally comes from factual information. Although some fans have not actually visited the 
idol-related places, they believe that the information published by the idols is consistent with the facts and trustworthy, and therefore have a more positive view of the sites. The establishment of emotional attitudes is more based on experiences and participation [8]. That is, fans' affection to the place can be cultivated and enhanced through actual visits. At this point, their attachment to the idol and the initial cognitive perception of the idol-related places will turn into emotional perception of the place itself after actual experience and deeper involvement, thus generating satisfaction and loyalty.

Emotional components play a very important role in the generation of intentions and decisions and taking practical tourism behavior $[18,66]$. In other words, positive emotions make them more likely to take determined choices. The support of the three hypotheses of H9 to H11 confirms this view. Moreover, it is not difficult to see from the values that place attachment has the greatest impact on destination preference. It follows that fans are more inclined to choose the country where the idol-related places are located due to their attachment and fondness.

Moreover, the results show that the actual visitation due to idols helped them have a preference for destination and information sharing related to the destination. For fans, their favorite idols played a significant role in strengthening a positive image of the destination. The impact of actual visitation on destination preference is another interesting dimension to the research findings. The idol attachment has successfully led tourists to actually prefer the destination and share information of destination, which helps the fans experience destination culture and create the image. This destination related to idols might develop its brand strategy for the future based on a more experiential and sustainable perspective.

\section{Implications and Limitations}

\subsection{Theoretical Implications}

First of all, the theory of sense of place has been widely used in the field of tourism, and it contains rich structure and dimensions, involving cognitive dimensions and affective dimensions. Some studies have examined the specific factors of sense of place and developed measurement standards, while others have selected some of these dimensions to study the place. The dimensions in sense of place applied in this paper involve place identity, place dependence, social bonding and atmosphere, and these four are functional and cognitive dimensions, and this is not common in previous discussions. Most of the destinations explored by sense of place are distinctive or symbolic in nature, or there is a close connection between these places and celebrities. The research objects in this paper are idol-related places, and are originally some facilities and places that can be seen everywhere in life, such as coffee shops, bookstores, convenience stores and parks. However, due to the temporary visit of the idols, these places have different meanings for fans than other similar places. The "pilgrimage" of fans has a long history, but the large-scale fan tourism activities triggered by these otherwise unremarkable places have not been fully studied. This may also be attributed to the development of social networks and the improvement of people's living standards.

Second, the substructures of sense of place and place attachment have many similarities and are often intermixed and substituted. This article discusses and reveals the process and mechanism of idols guiding fans to travel to a particular location. Tourists are influenced by many direct or indirect motivations in the process of choosing destination and taking action, and even the idols can be the main driving force. However, this study explores the complete transformation process of fans' attachment from idol to place, and finally explains the generation of behavioral intention. There are many researches on celebrity-induced tourism and the influence of celebrities on tourists' behavioral intention based on the phenomenon of the Korean Wave, but there are few studies involving the conversion process of affective-cognitive-affective. The contribution of this research is to verify the specific phase and process in which fans' attachment to idols can be transformed into a series of intentions. At the same time, there is often no clear distinction between the similar concepts involved in sense of place and place attachment theory in many studies. This 
research takes into account the four cognitive and functional dimensions of sense of place, and confirms the sequence of cognitive and affective factors, that is, sense of place triggers and promotes place attachment. This is consistent with the study of Brocato et al. [8].

Third, although the Korean Wave seems to be a popular culture among young people, it is also a very important part of the spread and extension of Korean culture. The visit of fans to idol-related places can also be seen as part of cultural tourism. These ubiquitous locations allow fans and visitors to immerse themselves into the local culture and create opportunities to learn more about the country and region. Moreover, the results of this study demonstrate that attachment to a specific place can promote visitors' purchasing intention, destination preference and information sharing intention. From the conclusion that place attachment has the greatest impact on destination preference, it is possible to improve the overall image and reputation of a country or a region by cultivating emotional attitudes towards local areas.

\subsection{Practical Implication}

The form of fan tourism with idol-related places as destinations, mainly takes the idol as the initial motivation, and takes the social networks, music videos, variety shows and life photos as carriers and communication channels. The definition of media is very broad, and the popularity of the Internet has accelerated the speed of information dissemination, so that the content produced in various forms of media can be quickly known by more people. When fans get information about idols, products or places related to idols become objects of their concern. Fans' positive attitude towards idols affects their perception of places and even destinations. This is a process from people to things/destinations. Therefore, it has become an issue worth discussing to promote the non-traditional tourist hot spots by idols, thus to enhance the popularity and reputation of different regions.

In the study of celebrities and sense of place, "place" refers more to the sites that are closely related to celebrities, such as the former residence of celebrities, the industry run by celebrities, or the place where celebrities work daily. In this study, the subjects were randomly visited by idols. These places are not owned by idols and they only occasionally appear. Even so, these places still attract fans' visits. Therefore, "pilgrimage" is no longer limited to traditional places with extremely strong symbolic significance, but is increasingly involved in daily life and surrounding places, becoming a popular tourist phenomenon among fans. According to this point of view, diversified tourism destinations can promote tourists' in-depth experience of local culture and can alleviate the environmental and order pressure of traditional tourist attractions at the same time.

Among output results of purchase intention, destination preference and information sharing, place attachment has the greatest impact on destination preference. Fans will have a preference for a country or region out of their attachment to the idol-related places, which has practical significance in destination promotion and marketing. It is important to establish a comprehensive and complete destination/national image, but sometimes the overall image can be improved through the construction of some specific or more targeted sites. This provides more diversified ideas for destination marketing. After all, there are very few visitors who can travel around every corner of a city or country in practice, while fragmented exposure and publicity can bring the effect of "love me and love my dog". This is a good way to save costs and improve efficiency. The objects involved in the subsequent behavior intention of tourists are other fans or people, which is another process from the things/places to the person. Therefore, from the perspective of practice, it is possible to promote the diversification of tourism forms and the in-depth exploration of tourist sites through the rational use of idols as publicity resources and cultural media, and finally bring more economic benefits, better public praise and more positive destination images.

\subsection{Limitations and Future Researches}

Although this research has some academic contributions and practical significance, its limitations still exist and cannot be ignored. First of all, the sample data of this study is 
relatively simple: only fans are selected as research objects and the vast majority of them are women. Generally speaking, fans are more likely to be influenced by idols than ordinary visitors due to their attachment and love for idols [39]. How to expand the scope of the research object to ordinary tourists is a problem that needs to be solved in future research.

On the other hand, although online surveys can reach a wider range of respondents at a faster speed, the lack of offline surveys in this study has also become a hindrance to the promotion of research results. The responses of online surveys are based on pre-visit expectations and post-visit memories. The perception of visitors will change with time, place and other factors, so the attitude and opinion generated while traveling are equally important [93]. Combining online and offline surveys, tourists' cognition and psychology can be explained more comprehensively.

Finally, because this survey is based on Chinese social networks, there is a lack of research on fans and visitors from other regions and countries. In general, the distance between the destination and the difference in cultural background may have an impact on the perception of destination image and the selection of tourism activities [94]. The survey participants in this study were limited to Chinese fans and tourists, and could not represent other tourists, which also greatly affected the universality of this study.

Nonetheless, it is important to note that the popularity of Korean idols is not necessarily limited to China but also very high in other countries (e.g., Japan, Hong Kong, and Europe). In a post-industrial society driven by popular culture, celebrities, including idols, are moving icons that instantly draw people's attention and actual visitation to the place they appear [18]. With the increasing circulation of popular culture worldwide, the socio-cultural and political power of celebrities will become even greater in the future. It is hoped that in future research, the respondents can involve more tourists from different countries and regions, so as to achieve the fairness and universality of research.

Author Contributions: Conceptualization, C.K. and J.-Y.K., introduction, literature Reviews, and methodology, J.Z.; Implications and Limitations, Y.Y.; methodology and validation, E.K. All authors have read and agreed to the published version of the manuscript.

Funding: National Research Foundation of Korea: This work was supported by the Ministry of Education of the Republic of Korea and the National Research Foundation of Korea (NRF-2019S1A3A2098438).

Institutional Review Board Statement: Not applicable.

Informed Consent Statement: Not applicable.

Data Availability Statement: Not applicable.

Conflicts of Interest: The authors declare no conflict of interest.

\section{References}

1. Sabre, C. French Anime and Manga Fans in Japan: Pop culture tourism, media pilgrimage, imaginary. Int. J. Contents Tour. 2017, 1,1-19.

2. Keller, K.L.; Parameswaran, M.G.; Jacob, I. Strategic Brand Management: Building, Measuring, and Managing Brand Equity; Pearson Education India: Delhi, India, 2011; ISBN 8131756890.

3. Ilicic, J.; Webster, C.M. Effects of multiple endorsements and consumer-celebrity attachment on attitude and purchase intention. Australas. Mark. J. 2011, 19, 230-237. [CrossRef]

4. Han, H.; Lee, J. A study on the KBS TV drama Winter Sonata and its impact on Korea's Hallyu tourism development. J. Travel Tour. Mark. 2008, 24, 115-126. [CrossRef]

5. Sandvoss, C. Fans: The Mirror of Consumption; Polity: Cambridge, UK, 2005; ISBN 0745629725.

6. Miller, R.K.; Washington, K.D.; Miller, R.K. The 2007 Travel E Tourism Market Research Handbook; Richard K. Miller \& Associates: Miramar, FL, USA, 2006; ISBN 1577831098.

7. Sönmez, S.; Sirakaya, E. A distorted destination image? The case of Turkey. J. Travel Res. 2002, 41, 185-196. [CrossRef]

8. Brocato, E.D.; Baker, J.; Voorhees, C.M. Creating consumer attachment to retail service firms through sense of place. J. Acad. Mark. Sci. 2015, 43, 200-220. [CrossRef]

9. Morgan, P. Towards a developmental theory of place attachment. J. Environ. Psychol. 2010, 30, 11-22. [CrossRef]

10. Altman, I.; Low, S.M. Place Attachment. Springer Science \& Business Media: Berlin/Heidelberg, Germany, 2012; Volume 12, ISBN 1468487531. 
11. Lee, P.; Hunter, W.C.; Chung, N. Smart Tourism City: Developments and Transformations. Sustainability 2020, 12, 3958. [CrossRef]

12. Kim, H.; Richardson, S.L. Motion picture impacts on destination images. Ann. Tour. Res. 2003, 30, 216-237. [CrossRef]

13. Mercille, J. Media effects on image: The case of Tibet. Ann. Tour. Res. 2005, 32, 1039-1055. [CrossRef]

14. Santos, C.A. FRAMING PORTUGAL: Representational Dynamics. Ann. Tour. Res. 2004, 31, 122-138. [CrossRef]

15. Boon, S.D.; Lomore, C.D. Admirer-celebrity relationships among young adults explaining perceptions of celebrity influence on identity. Hum. Commun. Res. 2001, 27, 432-465. [CrossRef]

16. Prentice, R.; Andersen, V. Evoking Ireland: Modeling tourism propensity. Ann. Tour. Res. 2000, 27, 490-516. [CrossRef]

17. Prentice, R. Tourist familiarity and imagery. Ann. Tour. Res. 2004, 31, 923-945. [CrossRef]

18. Lee, S.; Scott, D.; Kim, H. Celebrity fan involvement and destination perceptions. Ann. Tour. Res. 2008, 35, 809-832. [CrossRef]

19. Baloglu, S. Image variations of Turkey by familiarity index: Informational and experiential dimensions. Tour. Manag. 2001, 22, 127-133. [CrossRef]

20. Chen, C.-F.; Tsai, D. How destination image and evaluative factors affect behavioral intentions? Tour. Manag. 2007, 28, 1115-1122. [CrossRef]

21. Lee, C.-K.; Lee, Y.-K.; Lee, B. Korea's destination image formed by the 2002 World Cup. Ann. Tour. Res. 2005, 32, 839-858. [CrossRef]

22. Hausmann, A.; Slotow, R.O.B.; Burns, J.K.; Di Minin, E. The ecosystem service of sense of place: Benefits for human well-being and biodiversity conservation. Environ. Conserv. 2016, 43, 117-127. [CrossRef]

23. Reader, I. Pilgrimage growth in the modern world: Meanings and implications. Religion 2007, 37, 210-229. [CrossRef]

24. Bowlby, J. The making and breaking of affectional bonds: II. Some principles of psychotherapy: The Fiftieth Maudsley Lecture (expanded version). Br. J. Psychiatry 1977, 130, 421-431. [CrossRef]

25. Hazan, C.; Shaver, P. Romantic love conceptualized as an attachment process. J. Personal. Soc. Psychol. 1987, 52, 511. [CrossRef]

26. Thomson, M.; MacInnis, D.J.; Whan Park, C. The ties that bind: Measuring the strength of consumers' emotional attachments to brands. J. Consum. Psychol. 2005, 15, 77-91. [CrossRef]

27. Slater, J.S. Collecting brand loyalty: A comparative analysis of how Coca-Cola and Hallmark use collecting behavior to enhance brand loyalty. ACR N. Am. Adv. 2001, 28, 362-369.

28. Bowlby, E.J.M. Loss-Sadness and Depression: Attachment and Loss; Random House: New York, NY, USA, 2008; Volume 3, ISBN 140902024X.

29. Giles, D.C.; Maltby, J. The role of media figures in adolescent development: Relations between autonomy, attachment, and interest in celebrities. Personal. Individ. Differ. 2004, 36, 813-822. [CrossRef]

30. Kim, H.-W.; Zheng, J.R.; Gupta, S. Examining knowledge contribution from the perspective of an online identity in blogging communities. Comput. Hum. Behav. 2011, 27, 1760-1770. [CrossRef]

31. Chung, N.; Nam, K.; Koo, C. Examining information sharing in social networking communities: Applying theories of social capital and attachment. Telemat. Inform. 2016, 33, 77-91. [CrossRef]

32. Ramkissoon, H.; Smith, L.D.G.; Kneebone, S. Visitor satisfaction and place attachment in national parks. Tour. Anal. 2014, 19, 287-300. [CrossRef]

33. Kyle, G.; Graefe, A.; Manning, R. Testing the dimensionality of place attachment in recreational settings. Environ. Behav. 2005, 37, 153-177. [CrossRef]

34. Silvera, D.H.; Austad, B. Factors predicting the effectiveness of celebrity endorsement advertisements. Eur. J. Mark. 2004, 38, 1509-1526. [CrossRef]

35. Su, H.J.; Huang, Y.-A.; Brodowsky, G.; Kim, H.J. The impact of product placement on TV-induced tourism: Korean TV dramas and Taiwanese viewers. Tour. Manag. 2011, 32, 805-814. [CrossRef]

36. Hinerman, S. 'I'll Be Here With You': Fans, Fantasy and the Figure of Elvis. In The Adoring Audience; Taylor \& Francis Group: Abingdon, UK, 2002; p. 107.

37. Kim, S. Audience involvement and film tourism experiences: Emotional places, emotional experiences. Tour. Manag. 2012, 33, 387-396. [CrossRef]

38. Wong, J.; Lai, T. Celebrity attachment and behavioral intentions: The mediating role of place attachment. Int. J. Tour. Res. 2015, 17, 161-170. [CrossRef]

39. Hao, X.; Ryan, C. Interpretation, film language and tourist destinations: A case study of Hibiscus Town, China. Ann. Tour. Res. 2013, 42, 334-358. [CrossRef]

40. McCracken, G. Who is the celebrity endorser? Cultural foundations of the endorsement process. J. Consum. Res. 1989, 16, 310-321. [CrossRef]

41. Lee, J.; Kyle, G.; Scott, D. The mediating effect of place attachment on the relationship between festival satisfaction and loyalty to the festival hosting destination. J. Travel Res. 2012, 51, 754-767. [CrossRef]

42. Park, C.W.; MacInnis, D.J.; Priester, J.R. Beyond attitudes: Attachment and consumer behavior. Seoul Natl. J. 2006, $12,3-36$.

43. Reinartz, W.; Kumar, V. The mismanagement of customer loyalty. Harv. Bus. Rev. 2002, 80, 86-94.

44. Harvey, D.J.; Merry, A.H.; Royle, L.; Campbell, M.P.; Rudd, P.M. Justice, Nature E the Geography of Difference; Wiley-Blackwell: Hoboken, NJ, USA, 1996.

45. Sack, R.D. The consumer's world: Place as context. Ann. Assoc. Am. Geogr. 1988, 78, 642-664. [CrossRef]

46. Massey, D. Landscape as a provocation: Reflections on moving mountains. J. Mater. Cult. 2006, 11, 33-48. [CrossRef] 
47. Low, S.M.; Altman, I. Place attachment. In Place Attachment; Springer: Berlin/Heidelberg, Germany, $1992 ;$ pp. 1-12.

48. Casey, E.S. Between geography and philosophy: What does it mean to be in the place-world? Ann. Assoc. Am. Geogr. 2001, 91, 683-693. [CrossRef]

49. Deutsch, K.; Yoon, S.Y.; Goulias, K. Modeling travel behavior and sense of place using a structural equation model. J. Transp. Geogr. 2013, 28, 155-163. [CrossRef]

50. Tuan, Y.-F. Topophilia: A Study of Environmental Perceptions, Attitudes, and Values; Columbia University Press: New York, NY, USA, 1990; ISBN 0231513283.

51. Stedman, R.C. Toward a social psychology of place: Predicting behavior from place-based cognitions, attitude, and identity. Environ. Behav. 2002, 34, 561-581. [CrossRef]

52. Pretty, G.H.; Chipuer, H.M.; Bramston, P. Sense of place amongst adolescents and adults in two rural Australian towns: The discriminating features of place attachment, sense of community and place dependence in relation to place identity. J. Environ. Psychol. 2003, 23, 273-287. [CrossRef]

53. Davenport, M.A.; Anderson, D.H. Getting From Sense of Place to Place-Based Management: An Interpretive Investigation of Place Meanings and Perceptions of Landscape Change. Soc. Nat. Resour. 2005, 18, 625-641. [CrossRef]

54. Azizi, F.; Shekari, F. Modeling the Relationship between Sense of Place, Social Capital and Tourism Support. Iran. J. Manag. Stud. 2018, 11, 547-572. [CrossRef]

55. Eaton, W.M.; Eanes, F.R.; Ulrich-Schad, J.D.; Burnham, M.; Church, S.P.; Arbuckle, J.G.; Cross, J.E. Trouble with Sense of Place in Working Landscapes. Soc. Nat. Resour. 2019, 32, 827-840. [CrossRef]

56. Proshansky, H.M. The City and Self-Identity. Environ. Behav. 1978, 10, 147-169. [CrossRef]

57. Tajfel, H.; Turner, J. The Social Identity Theory of Inter-group Behavior. In Psychology of Intergroup Relations; Worchel, S., Austin, L.W., Eds.; Nelson-Hall: Chicago, IL, USA, 1986.

58. Cheng, V.; Ng, E.; Chan, C.; Givoni, B. Outdoor thermal comfort study in a sub-tropical climate: A longitudinal study based in Hong Kong. Int. J. Biometeorol. 2012, 56, 43-56. [CrossRef]

59. Gu, H.; Ryan, C. Place attachment, identity and community impacts of tourism-The case of a Beijing hutong. Tour. Manag. 2008, 29, 637-647. [CrossRef]

60. Therkelsen, A.; Halkier, H.; Jensen, O.B. Branding Aalborg: Building community or selling place? In Towards Effective Place Brand Management; Edward Elgar Publishing: Cheltenham, UK, 2010; pp. 136-155. ISBN 1848442424.

61. Stokols, D. People in places: A transactional view of settings. Cogn. Soc. Behav. Environ. 1981, 441-488.

62. Backlund, E.A.; Williams, D.R. A quantitative synthesis of place attachment research: Investigating past experience and place attachment. In Proceedings of the 2003 Northeastern Recreation Research Symposium, Bolton, MA, USA, 6-8 April 2003.

63. Jorgensen, B.S.; Stedman, R.C. Sense of place as an attitude: Lakeshore owners attitudes toward their properties. J. Environ. Psychol. 2001, 21, 233-248. [CrossRef]

64. Yi, X.; Fu, X.; Jin, W.; Okumus, F. Constructing a model of exhibition attachment: Motivation, attachment, and loyalty. Tour. Manag. 2018, 65, 224-236. [CrossRef]

65. Ramkissoon, H.; Weiler, B.; Smith, L.D.G. Place attachment and pro-environmental behaviour in national parks: The development of a conceptual framework. J. Sustain. Tour. 2012, 20, 257-276. [CrossRef]

66. Jin, M.-L. The effect of attachment to Hallyu on Chinese tourists to revisit and to recommend Korea based on transfer theory. Int. J. Tour. Hosp. Res. 2017, 31, 19-31. [CrossRef]

67. Kim, S. Extraordinary experience: Re-enacting and photographing at screen tourism locations. Tour. Hosp. Plan. Dev. 2010, 7, 59-75. [CrossRef]

68. Lee, D.E.; Jin, M.L.; Lee, C.K. Estimating the economic value of Hallyu experience using CVM: Valuation of Hallyu for Chinese tourists. Korean Tour. Res. 2015, 30, 163-182.

69. Yen, C.-H.; Croy, W.G. Film tourism: Celebrity involvement, celebrity worship and destination image. Curr. Issues Tour. 2016, 19, 1027-1044. [CrossRef]

70. Hosany, S.; Ekinci, Y.; Uysal, M. Destination image and destination personality: An application of branding theories to tourism places. J. Bus. Res. 2006, 59, 638-642. [CrossRef]

71. Bhattacharya, C.B.; Sen, S. Consumer-company identification: A framework for understanding consumers' relationships with companies. J. Mark. 2003, 67, 76-88. [CrossRef]

72. Williams, D.R.; Vaske, J.J. The measurement of place attachment: Validity and generalizability of a psychometric approach. For. Sci. 2003, 49, 830-840.

73. Hidalgo, M.C.; Hernandez, B. Place attachment: Conceptual and empirical questions. J. Environ. Psychol. 2001, 21, $273-281$. [CrossRef]

74. Rosenbaum, M.S.; Ward, J.; Walker, B.A.; Ostrom, A.L. A cup of coffee with a dash of love: An investigation of commercial social support and third-place attachment. J. Serv. Res. 2007, 10, 43-59. [CrossRef]

75. Kim, S.; Kim, S.; Han, H. Effects of TV drama celebrities on national image and behavioral intention. Asia Pacific J. Tour. Res. 2019, 24, 233-249. [CrossRef]

76. Robinson, P. I remember it well: Epiphanies, nostalgia, and urban exploration as mediators of tourist memory. Tour. Cult. Commun. 2015, 15, 87-101. [CrossRef] 
77. Park, C.W.; MacInnis, D.J.; Priester, J.; Eisingerich, A.B.; Iacobucci, D. Brand attachment and brand attitude strength: Conceptual and empirical differentiation of two critical brand equity drivers. J. Mark. 2010, 74, 1-17. [CrossRef]

78. Mao, I.Y.; Zhang, H.Q. Structural relationships among destination preference, satisfaction and loyalty in Chinese tourists to Australia. Int. J. Tour. Res. 2014, 16, 201-208. [CrossRef]

79. Kil, N.; Holland, S.M.; Stein, T.V.; Ko, Y.J. Place attachment as a mediator of the relationship between nature-based recreation benefits and future visit intentions. J. Sustain. Tour. 2012, 20, 603-626. [CrossRef]

80. Hasanov, M.; Beaumont, J. The value of collective intentionality for understanding urban self-organization. Urban Res. Pract. 2016, 9, 231-249. [CrossRef]

81. Ren, Y.; Harper, F.M.; Drenner, S.; Terveen, L.; Kiesler, S.; Riedl, J.; Kraut, R.E. Building member attachment in online communities: Applying theories of group identity and interpersonal bonds. MIS Q. 2012, 841-864. [CrossRef]

82. Wasko, M.M.; Faraj, S. Why should I share? Examining social capital and knowledge contribution in electronic networks of practice. MIS Q. 2005, 35-57. [CrossRef]

83. Ham, J.; Koo, C.; Chung, N. Configurational patterns of competitive advantage factors for smart tourism: An equifinality perspective. Curr. Issues Tour. 2020, 23, 1066-1072. [CrossRef]

84. Wu, H.-C.; Cheng, C.-C. Relationships between technology attachment, experiential relationship quality, experiential risk and experiential sharing intentions in a smart hotel. J. Hosp. Tour. Manag. 2018, 37, 42-58. [CrossRef]

85. Churchill, G.A., Jr. A paradigm for developing better measures of marketing constructs. J. Mark. Res. 1979, 16, 64-73. [CrossRef]

86. Vinzi, V.E.; Chin, W.W.; Henseler, J.; Wang, H. Handbook of Partial Least Squares; Springer: Berlin, Germany, 2010.

87. Um, T.; Chung, N. Does smart tourism technology matter? Lessons from three smart tourism cities in South Korea. Asia Pac. J. Tour. Res. 2019, 1-19. [CrossRef]

88. Anderson, J.C.; Gerbing, D.W. Structural Equation Modeling in Practice: A Review and Recommended Two-Step Approach. Psychol. Bull. 1988, 103, 411-423. [CrossRef]

89. Fornell, C.; Larcker, D.F. Evaluating Structural Equation Models with Unobservable Variables and Measurement Error. J. Mark. Res. 1981, 18, 39-50. [CrossRef]

90. Hair, J.F.; Black, W.C.; Babin, B.J.; Anderson, R.E.; Tatham, R. Multivariate Data Analysis; Pearson Prentice Hall: Uppersaddle River, NJ, USA, 2006.

91. Hulland, J. Use of partial least squares (PLS) in strategic management research: A review of four recent studies. Strateg. Manag. J. 1999, 20, 195-204. [CrossRef]

92. Hair, J.F.; Ringle, C.M.; Sarstedt, M. PLS-SEM: Indeed a silver bullet. J. Mark. Theory Pract. 2011, 19, 139-152. [CrossRef]

93. Park, S.; Santos, C.A. Exploring the Tourist Experience: A Sequential Approach. J. Travel Res. 2017, 56, 16-27. [CrossRef]

94. Yu, J.Y.; Ko, T.G. A cross-cultural study of perceptions of medical tourism among Chinese, Japanese and Korean tourists in Korea. Tour. Manag. 2012, 33, 80-88. [CrossRef] 